\title{
Neurology education and global health My rotation in Botswana
}

\author{
Nabila Dahodwala, MD
}

The University of Pennsylvania's Department of Infectious Diseases received an HIV education grant through the President's Emergency Plan for AIDS Relief in 2002. Since then, they have established a permanent clinical and educational program at the main public hospital in Gaborone, Botswana. An attending faculty member resides in Gaborone year-round, and additional infectious disease specialists, fellows, medical residents, and students rotate through the hospital. A team of Penn doctors and students admit patients to the medical ward, care for them through discharge, and often follow them up as outpatients. They have recently invited neurologists to assist in their efforts, and as a fourth-year resident, I spent 5 weeks there in the spring of 2006 . To date, three Penn-affiliated and one non-Penn-affiliated neurology residents have participated in the program.

Botswana is a parliamentary republic in southern Africa (figure). Most of the 1.7 million residents are Setswana, whereas the other ethnic groups include Basarwa (bushmen), Kalanga, and Caucasians. Botswana represents one of the few African countries to have sustained high rates of socioeconomic and infrastructure growth over its 40 years of independence. It provides free healthcare and education to all

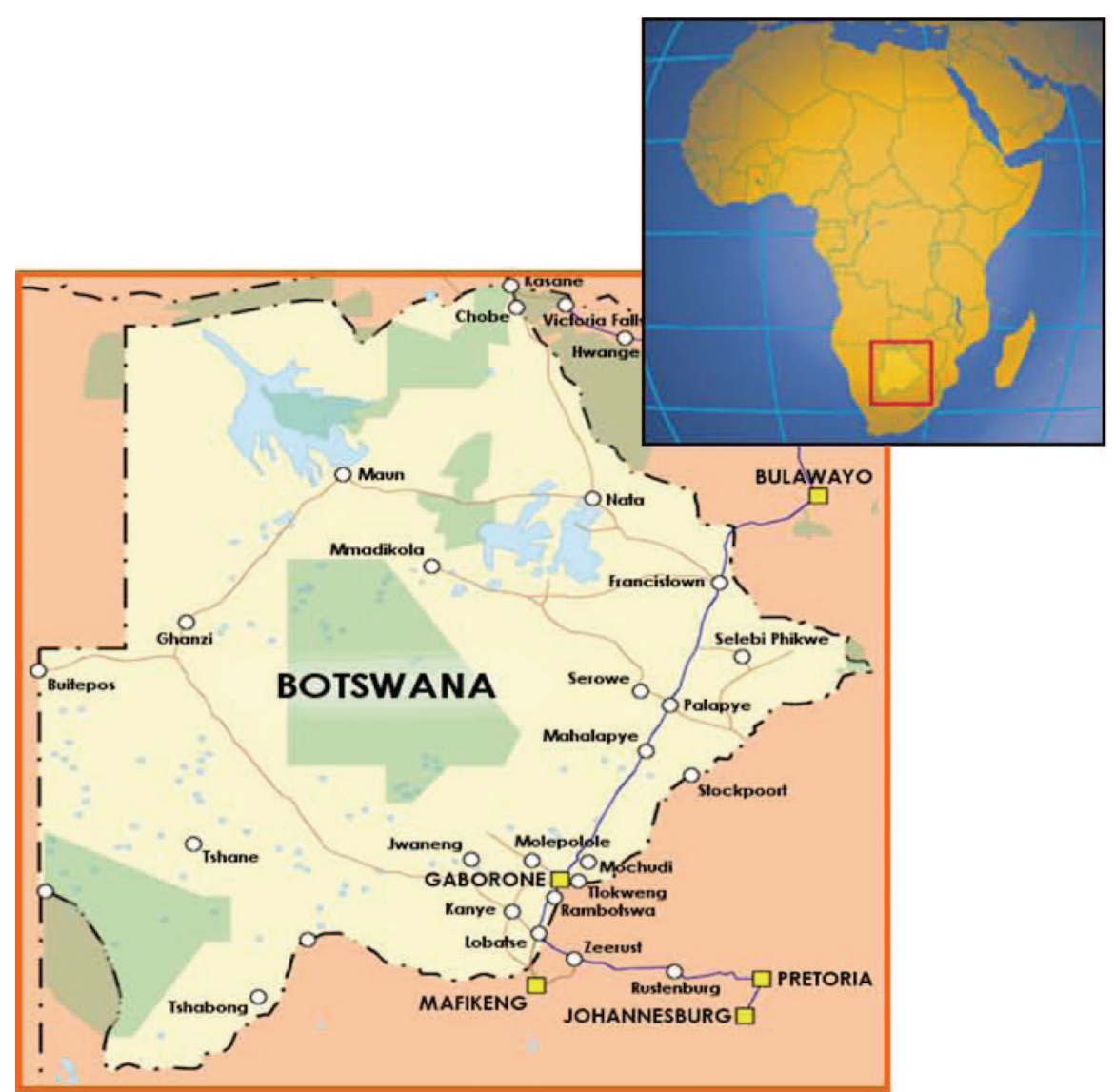

Figure. Map of Botswana.

residents. However, Botswana has one of the highest prevalences of HIV in the world at $24 \%$ in adults. ${ }^{1}$ Recently, the government has started to cover antiretroviral therapy through its outpatient clinics, but it has been slow to reach all those in need.

Among HIV-infected patients,
10 to $20 \%$ initially present with neurologic symptoms, and up to $70 \%$ will have neurologic disease during the course of their illness. ${ }^{2}$ In addition, both HIV-infected and noninfected patients are at risk for non-HIV-related neurologic disease. The Batswana (the people of Botswana) have high

From the Robert Wood Johnson Clinical Scholars Program, University of Pennsylvania, Philadelphia.

Supported by the University of Pennsylvania Department of Infectious Diseases (funding for travel) and Robert Wood Johnson Foundation (salary).

Disclosure: The author reports no conflicts of interest.

Received August 11, 2006. Accepted in final form November 27, 2006.

Address correspondence and reprint requests to Dr. N. Dahodwala, Robert Wood Johnson Clinical Scholars Program, University of Pennsylvania, 423 Guardian Dr., Blockley Hall, 13th fl., Philadelphia, PA 19104; e-mail: nabila.dahodwala@uphs.upenn.edu 
rates of hypertension, diabetes, heart disease, stroke, cancer, cognitive dysfunction, and epilepsy. However, there are no neurologists in Botswana, nor are there medical schools or neurology residency training programs. This combination has led to little recording and no publications about the basic epidemiology or burden of neurologic disease.

During my rotation, I would review all the cases that were admitted from the previous day with the Botswana and Penn house staff. Routinely through this morning intake, there were 5 to 10 neurologic cases presented: acute-onset weakness, progressive weakness, unsteady gait, seizures, headache, and confusion. I maintained a patient log of the new cases I encountered during my time at the hospital. Of the 98 cases that I recorded, $29(30 \%)$ presented with seizure, 21 (21\%) with ischemic stroke, $12(12 \%)$ with neuropathy, $9(9 \%)$ with intracranial hemorrhage, $6(6 \%)$ with intracranial mass, and $6(6 \%)$ with myelopathy. I also saw two cases of snake bites, one case of organophosphate poisoning, and two cases of immunereconstitution syndrome. About $75 \%$ of these patients were HIVpositive. Diagnoses were based on history and exam, and rarely was quick and reliable blood or CSF testing available. Head CT scans could take up to 1 week to obtain, and there was no EEG, electromyography/nerve conduction studies, or MRI equipment.

Within the constraints of limited testing, I relied heavily on the history and exam to guide diagnosis and management. My clinical exam skills sharpened, and the scope of my differential diagnoses widened to include tuberculosis, parasitic (i.e., malaria) and fungal infections, nutritional deficiencies, complications from traditional medicines, and HIVrelated complications. Unfortunately, therapeutic options remained limited; supplies often ran out and neurosurgical services were nonexistent in Gaborone.

The demand for neurologic clinical skills was high. In addition to seeing inpatients, my role expanded to include private patients from outside clinics, outpatient follow-ups, and even the chance family member of a hospital employee. The patients were responsible, respectful, appreciative, and eager to learn. Language proved to be the biggest barrier in obtaining the history and discussing results and plans. Most older patients spoke only Setswana, though a growing number of the younger patients could understand, and often, speak English. Although less than an ideal solution, nurses were called upon to act as translators. Throughout my 5 weeks, I discovered that patient and family education was one of the more valuable services I had to offer.

Because there was also a high demand for education of the house staff, teaching became another integral part of my job. The medical house staff had all completed medical school and had varying degrees of clinical experience. Most expressed discomfort with performing the neurologic exam, interpreting head CT scans, and diagnosing and managing common neurologic diseases. I started with a series of formal lectures focused on basic topics (e.g., a review of the neurologic exam and acute stroke management). As my time there progressed, and as I saw more cases, I gave talks on seizure management in HIV-positive patients and HIV myelopathy.

On my return to the United States, I flew directly to San Diego, CA, for the 2006 AAN meeting. Surrounded by more than 11,000 neurologists, I was amazed by the cutting-edge research and wealth of resources. We have the extraordinary opportunity to leverage this wealth to change how people with neurologic diseases are cared for globally. First, we can expand our research on the neurologic complications of HIV to include cheaper diagnostic tests and treatments that would be sustainable in the developing world. Sec- ond, we can add to the resources in these countries by providing supplies, but especially by providing neurologically trained healthcare providers. We should develop educational programs to increase knowledge of neurologic diseases. By establishing exchange programs with local providers and cultivating study abroad opportunities, we will be able to provide and improve neurologic care in Botswana and other resourcepoor countries.

Residents and fellows who study abroad will be providing essential services to an underserved population and education for local providers. At the same time, they will add to their training by improving clinical and teaching skills and increasing exposure to the neurologic complications of HIV. Bergen and Silberberg comment in their editorial "Nervous system disorders: a global epidemic" that "in many regions, centers of ... neurologic excellence and expertise are needed, not only to help plan research and prevention strategies appropriate for local needs, but also to educate the primary health care providers who care for most disorders of the nervous system."3 Both the AAN and individual training programs should support these efforts. This support should include travel funding and allow for time away from clinical responsibilities at one's home institution. The AAN might even consider establishing international neurology grants for clinical rotations, education, and research abroad. Improving global health and providing equity in care is a daunting task, but we can help meet the challenge.

\section{Acknowledgment}

The author thanks Dr. Craig Pollack for his invaluable editing assistance.

\section{References}

1. 2006 report on the global AIDS epidemic www.unaids.org. Accessed June 15, 2006.

2. Berger JR, Levy RM. The neurological complications of human immunodeficiency virus infection. Med Clin North Am 1993;77:1-23.

3. Bergen DC, Silberberg D. Nervous system disorders: a global epidemic. Arch Neurol 2002;59:1194-1196. 


\section{Neurology}

\section{Neurology education and global health: My rotation in Botswana \\ Nabila Dahodwala \\ Neurology 2007;68;E15-E16 \\ DOI 10.1212/01.wnl.0000257827.43171.23}

\section{This information is current as of March 26, 2007}

\section{Updated Information \& Services}

References

Citations

Subspecialty Collections

Permissions \& Licensing

Reprints including high resolution figures, can be found at: http://n.neurology.org/content/68/13/E15.full

This article cites 2 articles, 0 of which you can access for free at: http://n.neurology.org/content/68/13/E15.full\#ref-list-1

This article has been cited by 4 HighWire-hosted articles: http://n.neurology.org/content/68/13/E15.full\#\#otherarticles

This article, along with others on similar topics, appears in the following collection(s):

\section{All Education}

http://n.neurology.org/cgi/collection/all_education

Information about reproducing this article in parts (figures,tables) or in its entirety can be found online at:

http://www.neurology.org/about/about_the_journal\#permissions

Information about ordering reprints can be found online:

http://n.neurology.org/subscribers/advertise

Neurology ${ }^{\circledR}$ is the official journal of the American Academy of Neurology. Published continuously since 1951, it is now a weekly with 48 issues per year. Copyright . All rights reserved. Print ISSN: 0028-3878. Online ISSN: 1526-632X.

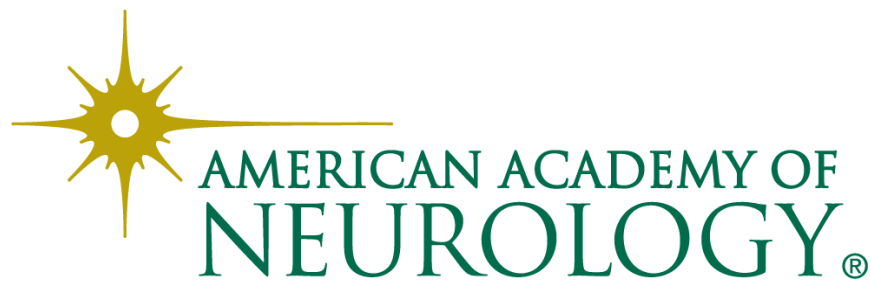

